\title{
Studying the Integration Level of Traditional Ecological Knowledge in Science Education: A Case Study in British Columbia, Canada in Grade 7 and 8 Official Curriculum Documents
}

\author{
Eun-Ji Amy Kim \\ University of Ottawa, Ontario, Canada
}

\begin{abstract}
The purpose of this research is to study how Traditional Ecological Knowledge (TEK) is represented in Grade 7 and 8 Official Science Curriculum in British Columbia, Canada. To illustrate prevalence and representation of TEK in the documents, a mixed methods framework of content analyses, Hermeneutic Content Analysis (HCA) wasl conducted. Furthermore, the advantages of integrating TEK in science curriculum will be discussed in this article.
\end{abstract}

\section{Introduction}

Traditional Ecological Knowledge (TEK) is described as a form of knowledge system in Indigenous Science which is orally transmitted in Indigenous communities that are directly related to local environment and people [1]. Battiste [2], lays down the significance of teaching Indigenous knowledge to all students. She states that: It [Indigenous knowledge] is not only a remedy to the continuing failures of the education system, but also the opening to understanding distinct knowledge that the twenty-first century education must learn to operate (p.87).

Aboriginal people have been intact with the environment for a long time. Despite the fact that TEK is essential for the maintenance of an environmental monitoring program for Aboriginals, because it is orally transmitted, communities have not had members educated in a system that values local knowledge [3]. Manitoba Education and Youth [3] suggests that incorporating TEK into the science curriculum provides "a foundation that validates local TEK along with Western science" (p.16). The importance of teaching TEK to all students has been emphasized especially by British Columbia ministry of education [4], as they state, "This knowledge [TEK] with its characteristic respect for sustaining community and environment offers proven conceptual approaches which are becoming increasing important to all BC residents" (p.11).

Many scientific scholars suggest that TEK is holistic by nature, and so can clearly complement conventional science [1]. Moreover, many researchers including Kimmerer [5], Hatcher, A.,
Bartlett, C., Marshall, A., and Marshall, M. [6] note that TEK is being recognized as having equal status with scientific knowledge. For example, the government of the Northwest Territories adopted a policy that recognized TEK as a valid source of knowledge that should be incorporated into territorial government where appropriate [1]. Not only two recent environmental impact assessments done by government of Canada were advised to give equal weighting to TEK as compared to Western science, the federal government of Canada announced that they would give equal standing to TEK with respect to Western science, in future environmental impact assessment process [1].

Indigenous Knowledge (IK) has been, however, historically marginalized in scientific community and continuously debated in the field regarding whether „indigenous"e, „traditional ${ }^{\text {ee }}$ or „local "e knowledge could be considered as ,science ec [5]. One of the most crucial factors that have been considered to be an obstacle to the integration of TEK within modern science is the assumption of the essential incommensurability between these two types of knowledge [7]. However many researchers argue that there are similarities between IK and WMS. Thus they are commensurable [3]. Based on Palys "s work [8], Tsuji and Ho [1] analyzed how TEK shares some similarities with WMS as well as how TEK can be thought of as ,science ee rather than lay-knowledge. Palys argues that there are four characteristics of scientific knowledge that distinguish themselves from lay-knowledge. According to Palys, scientific knowledge is "systematic, subject to peer and public review, part of a collective process, and selfreflexive" In their reports, Tsuji and Ho show how TEK contains all four characteristic of scientific knowledge suggested by Palys. For instance, TEK is systematic because "specific observations are gathered from certain activities during identified times of the year (e.g., caribou harvesting and distribution)" [1]. As a matter of fact, TEK is similar in many respects to the long-term observational data that have been referred to as natural history in WMS. Considered to be natural history, TEK has contributed to the formation of environmental science, ecology, biology, geology, and geography [3]. Here, we can see that TEK has contributed in many studies in various fields in WMS and that two 
sciences, IK and WMS can be in fact, commensurable.

While the issue of validity of TEK appears on the surface, the Brundtland Commission report [9], discusses common economic and environmental issues that our world needs to focus on. The report states that we need to draw special attention to lifestyle and knowledge, including TEK, of indigenous peoples. Aboriginal people in Canada have been lived intimate contact with nature, and they have acquired the knowledge to live in harmony with other creatures. As a result, indigenous people inhabit areas with some of the highest remaining biodiversity on the planet [5]. Kimmerer [5] also notes that TEK includes detailed observation of population ecology and species interaction; these observations can offer concrete evidence for contemporary interpretations of patterns in nature such as floods, tsunamis and earthquakes. TEK, therefore, is considered as a valuable teaching source because of the wealth of biological information it contains as well as the cultural framework of respect, reciprocity, and responsibility in which it is embedded.

With its significance and recognition given to TEK, it has been suggested for educational ministries to incorporate TEK into their provincial science curricula, and to promote learning TEK in local schools for providing better science education, especially for biology, ecology and environmental education. Integration of TEK in science education also has been suggested especially for enhancing Aboriginal students learning in science by providing culturally relevant content in curriculum. It has been argued that this culturally relevant curriculum (i.e., integrative science curriculum) can bring multicultural perspectives into the core of science curriculum which can help develop global citizenship for non-Aboriginal students as well.

Up until now, only few studies have been conducted through discursive analysis on textbooks, action research or observation of instructional strategies in science classrooms to give a better understanding of the importance and representation of TEK in documents [10]. However, no such study has been made for official science curriculum documents in Canada. Therefore, the objective of this study is:

- To study how and to what extent TEK is integrated into the official curriculum documents across the nation

- To explore how each provincial ministries of education perceive and treat TEK as scientific knowledge.

The focus has been placed in intermediate level particularly in science grades 7 to 10 . The data source will be discussed in details in Methodology section.

\section{Conceptual Framework}

Indigenous Science (IS) and Traditional Ecological Knowledge (TEK) have multiple meanings and there are no specific definitions to explain such concept [11]. However, for the clarity of this project, it is important to distinguish TEK from IS. In order to see the characteristics of IS and TEK, comparison of IS and TEK with Western Modern Science (WMS), the most dominant science in our actual world is necessary as well.

Indigenous Science Researchers, Snively and Corsiglia [11] explain TEK as "a subset of Indigenous Science (IS)” (p.8). In turn, Indigenous Science is often described as a system which interprets how the world works from a particular cultural perspective or science in a given culture [11]. Many authors including Aikenhead [10] suggest that every culture has its own science, thus science is a sub-culture of a community (or a society). Therefore, the term Indigenous Sciences is a plural term rather than a singular term because it represents the diversity of sciences related to the strongly rooted place-based traditions from their foundation [6]. IS has been also described as "a large range of coming to know processes that result from human experiences in the natural world" [6]. Traditional Ecological Knowledge, described as a subset of IS, is then representing experience acquired over years of direct human contact with the environment [11].

Indeed, the terms, Indigenous knowledge, Traditional Ecological (Environmental) Knowledge (TEK), Indigenous science, ecological wisdom and many others are used to describe the body of expertise and knowledge held in indigenous communities [3]. There is no specific definition for TEK. However, various researchers describe this form of understanding as a body of knowledge and beliefs transmitted through oral tradition and firsthand observation [2].TEK consists of a set of empirical observations about local environment, a system of classification, and a system of selfmanagement which governs resource use in local communities. Since the knowledge is based on local environment, the quantity and quality of TEK can be varied among community members, depending on gender, age, social status, intellectual capability, and profession [5]. Moreover, TEK is holistic; it views environmental aspects to be closely tied to social and spiritual aspects of knowledge systems. TEK is also both cumulative and dynamic. The knowledge is derived from long-term observational data and maintained through an oral tradition. TEK, therefore, builds upon the experience of earlier generations and adapts to new technological and socioeconomic changes of the present. With all its characteristics, TEK acts as a baseline of information on the local environment [1]. 
Nonetheless, some argue that the term, TEK is problematic. TEK is still in use today in many communities. The term "traditional", however brings connotation that it is only used in ancient times [12]. Some prefer the term Indigenous Knowledge (IK), which helps to avoid the debate about the term "traditional" and puts emphasis on indigenous people [11]. However, the term TEK is still widely used in many literatures and many scientists and educator refer such knowledge as TEK. For these reasons, I use the term Indigenous Knowledge (IK) and Traditional Ecological Knowledge (TEK) interchangeably in this paper. I also wish to acknowledge that I focus on TEK from Canada (geographical-specific) for this project. Therefore, I will use the term, Aboriginal people to address the indigenous people living in Canada.

In order to see the importance given to TEK in each provincial curriculum, both prevalence and representation of TEK need to be studied. As mentioned earlier, TEK can be seen complementary to WMS, bringing students a more holistic view of what is science and how science is related to cultural aspects; but it can also be seen as lay knowledge which normally brings condescension from learners. Therefore, there will be a search for the conception of TEK in the different provincial official science documents.

In comparing the aspects of TEK and WMS, Manitoba Education and Youth [3] identify that there is a common ground between two knowledge systems. They propose four different dimensions the common ground which are: a. Organizing principles (e.g., Ideas such as that the body of knowledge is stable but subject to modification or developing an understanding of the relationships between science and of the social and environmental contexts of science and technology), b. Habits of Mind (e.g., holistic), c. Skills and Procedures (e.g., observation) and d. Knowledge (e.g., animal behaviour). I believe that these aspects illustrated in common ground are the skills and knowledge that science education should be focusing on. Indeed, these four dimensions are also mentioned as content standards for science education system in BC curriculum documents [5]. The conceptual framework for this proposal is, therefore, based on these four dimensions of common ground between TEK and WMS and the characteristics of TEK mentioned in this paper. These dimensions will be useful to study the prevalence of TEK in the curriculum documents. Under these four common ground dimensions, I categorized the characteristics of TEK described by various authors (See Appendix I). These characteristics will serve as a guideline for the content analysis.

With this conceptual framework, I wish to explore curriculum documents, and identify TEK integrated in documents. However, as Kimmerer noted in his article, in order to protect and use TEK in a respectful and appropriate manner, "the identity of the practitioners, informants and the community should always be fully referenced and acknowledge with the same diligence that scientists apply to the contributions of their academic colleagues" [5]. Therefore, during my analysis, though curriculum applies to the characteristics of TEK mentioned in a chart, if there is no reference to this knowledge, I would not count it as the integration of TEK.

\section{Research Questions}

The main focus of this study is to examine the provincial curriculum documents from grades 7 and 8 in science. Within these documents, the following questions will guide the analysis of Aboriginal educational contents:

Descriptive Questions:

a) How prevalent is TEK contents in studied documents?

b) In which learning disciplines (i.e., curriculum organizers such as life science or physical science) is TEK content found in the studied documents table?

c) Based on the four dimensions (e.g., organizing principles, habits of mind, skills and procedures, knowledge) from the conceptual framework, which dimension has the most/ least TEK content?

Ontological/Epistemic Questions:

a) How is TEK conceptualized in the curriculum documents? (i.e. is it implicated in primitive or in modern/constructive ways?)

b) To which extent is TEK recognized by the ministry of education?

\section{Methodology}

Once all the documents were collected, data analysis was performed by the researcher alone. This study asks both quantitative and qualitative questions. Therefore, Hermeneutic Content Analysis (HCA), a mixed framework for content analyses, was used for this study. All data was reviewed concurrently since the process involves moving back and forth between the entire data set. At first, each curriculum document was analyzed individually for the second analytic process. The conclusion was drawn from the interpretation of both quantitative and qualitative analyses.

\section{Results}

Both Grade 7 and 8 acknowledge the importance and benefits of TEK. They both had a section called, „Integration of Aboriginal content in the prescribed learning outcomes ${ }^{\text {ee }}$ in order to show educators how 
valuable TEK is in our society, especially for teaching future generations about the environment. They [5] also noted that integrative science curriculum (i.e., curriculum that integrates both TEK and WMS) would "provide a meaningful context for aboriginal students and enhance the learning experience for all students" (p.10)

The documents state that, in order to overcome the difficulties of incorporating indigenous knowledge and worldviews into western science classroom, "the participants of the Ministry of Education Aboriginal Science meetings" suggest for a teaching model involving a parallel process. However, they failed to mention the participants present in that assembly. Were there any Aboriginal elders or scholars participating in the meeting? If so, why did not they acknowledge the participants in the documents? As mentioned previously, in indigenous communities, if the credit of information and knowledge shared is not given properly, it is not appropriate manner of sharing their knowledge in our classroom.

If there were not any Aboriginal scholars or elders involved in the meeting, it becomes problematic. Western educators would not understand indigenous knowledge and worldview thoroughly since they are orally transmitted. A further study on the participants and involvement of Aboriginal scholars and elders in curriculum design is needed to be conducted.

Both documents state that "to address these topics [cultures and contribution of Aboriginal people] in the classroom in a way that is accurate and that respectfully reflect Aboriginal concepts for teaching and learning, teachers are strongly encouraged to seek the advice and support of local Aboriginal communities" (p.16). However, they fail to provide specific information pertaining to the individuals that need to be contacted by teachers. They simply mentioned that teachers contact "Aboriginal education co-coordinators, teachers, support workers, and counselors in district who will be able to facilitate the indemnification of local resources and contacts such as elders, chiefs, tribal or band councils" (p.16). They provide a website which contains information consulting the Aboriginal Education Website. However, among the provided maps, resources and documents found on the website, there is no direct contact number for the district's Aboriginal education co-coordinators or elders. Therefore, teachers that needed to contact these specialists in their field so as to access valuable resources were simply left on their own in their quest for achieving this goal.

Out of eight resources used in the development of two studied documents, only one of them was dedicated to content related to Aboriginal knowledge and experiences Shared learning, published in 1998 by the Aboriginal Education Initiative, part of the
British Columbia Ministry of Education is the sole document contributing to curriculum. However, this document is out of dated. No culture is static. Pedagogies, technologies for teaching children evolve. They are using this document, which w published more than a decade ago, for the pourpose of incorporating worldviews and pedagogy for Aboriginal students. In order to see how much of the content of this document was incorporated in the curriculum, I decided to analyze the prevalence of TEK and pedagogies that incorporated Aboriginal worldviews.

Table 1 shows the prevalence of TEK in each curriculum organizer. Not much of TEK can be found in the curriculum; the ones found in the documents tend to be associated with life science and earth and space science.

Table 1. TEK found in each curriculum organizer

\begin{tabular}{|c|c|c|c|c|c|}
\hline & $\begin{array}{c}\text { Life } \\
\text { Science }\end{array}$ & $\begin{array}{c}\text { Physical } \\
\text { Science }\end{array}$ & $\begin{array}{c}\text { Earth and Space } \\
\text { Science }\end{array}$ & $\begin{array}{c}\text { Process } \\
\text { of } \\
\text { Science }\end{array}$ & Total \\
\hline Grade 7 & 7 & 0 & 0 & 0 & 7 \\
\hline Grade 8 & 2 & 2 & 5 & 2 & 11 \\
\hline
\end{tabular}

The types of TEK found in the studied documents are dedicated to promoting (teaching) skills and attitudes in science. None of the vocabulary to be learned in the classroom are associated with TEK. Some of the Knowledge was mentioned as a suggested achievement indicator (Table 3). However, they were never mentioned as a main knowledge to be learned (Table 2).

Table 2. TEK integrated in four domains of science education

\begin{tabular}{|c|c|c|c|c|}
\hline & $\begin{array}{c}\text { Habits of } \\
\text { mind }\end{array}$ & Knowledge & $\begin{array}{c}\text { Skills and } \\
\text { procedure }\end{array}$ & $\begin{array}{c}\text { Organizing } \\
\text { principle }\end{array}$ \\
\hline Grade 7 & 0 & 0 & 1 & 0 \\
\hline Grade 8 & 0 & 0 & 7 & 0 \\
\hline
\end{tabular}

Table 3. TEK found in assessment models

\begin{tabular}{|c|c|c|c|}
\hline & $\begin{array}{c}\text { Suggested } \\
\text { achievement } \\
\text { indicator }\end{array}$ & $\begin{array}{c}\text { Planning for } \\
\text { assessment }\end{array}$ & $\begin{array}{c}\text { Suggested } \\
\text { assessment } \\
\text { activities }\end{array}$ \\
\hline Grade 7 & 1 & 3 & 2 \\
\hline Grade 8 & 2 & 1 & 1 \\
\hline
\end{tabular}

Table 4. Number of Resources integrating Aboriginal perspectives and knowledge

\begin{tabular}{|c|c|}
\hline Grade 7 & 4 \\
\hline Grade 8 & 0 \\
\hline
\end{tabular}

As shown in Table 4, Out of 45 resources suggested, only 4 of them were associated with some form of TEK in Grade 7. None of the resources for Grade 8 were associated with TEK or any Aboriginal perspective. 


\section{Conclusion}

Despite the fact that TEK has been recognized as an important learning concept by both the education and scientific communities, there seems to be a lack of TEK incorporated in $\mathrm{BC}$ grade 7-8 science curriculum.

The Ministry of Education acknowledges the Knowledge shared in Aboriginal communities and encourages teachers to incorporate these values and knowledge. However, there is a lack of resources for teachers to incorporate them in their lessons.

Based on results, there seems to be a lack of TEK or any Aboriginal representation shown in science curriculum for grade 7 and 8 in BC.

The major limitation of this study is the actual pedagogies used in classrooms which remain unknown. This study assumes that teachers will follow the guideline suggested in official curriculum documents.

This study provides a glimpse of my final thesis project, which investigates the prevalence and representation of TEK in curriculum documents across Canada.

Although a number of general studies of Aboriginal content in curriculum exist, I have yet to come across a published study that has analyzed the prevalence and integration levels of Aboriginal knowledge and topics in official science curriculum documents in Canada. I strongly believe that my research project, which looks at the integration of indigenous knowledge and science can be relevant to Aboriginal communities as well as the current state of science education in Canada. This research project will also provide future researchers with data, which can be used as a basis for comparison with their results to judge if and how the coverage of Aboriginal topics and knowledge in Canadian science curriculum has changed over time. It also will help to re-articulate the strength and weakness of the knowledge within cross-cultural approach to science education.

\section{References}

[1] Tsuji, L. J. S., \& Ho, E. (2002). Traditional environmental knowledge and western science: in search of common ground. The Canadian Journal of Native Studies, 22(2), 227-260.

[2] Battiste, M. (2008). The struggle and Renaissance of Indigenous knowledge in Eurocentric Education. In M. Villegas., et.al. (Eds). Indigenous Knowledge and Education: Site of Struggle, Strength, and Survivance. Cambridge, MA: Harvard Education Publishing Group.

[3] Manitoba Education and Youth (2003). A Teacheres Guide for the Video Sila Alangotok- Inuit Observation on Climate Change [Data file] Retrieved from: http://www.edu.gov.mb.ca/k12/docs/support/sila_video/sil a_video.pdf

[4] British Columbia Ministry of Education (2005). Science Grade 7: From Integrated Resource Package 2005.

[5] Kimmerer, R. W. (2002). Weaving Traditional Ecological Knowledge into Biological Education: A Call to Action. BioScience. 52 (5) 432-438.

[6] Hatcher, A., Bartlett, C., Marshall, A., and Marshall, M. (2009). Two-Eyed Seeing in the Classroom Environment: Concepts, Approaches, and Challenges. Canadian Journal of Science, Mathematics and Technology Education, 9 (3), 141-153.

[7] Reis, G. \& Ng-A-Fook. N (2010). TEK talk: so what? Language and the decolonization of narrative gatekeepers of science education curriculum. Cultural Studies of Science Education. 5, 1009-1026.

[8] Palys, T. (1997). Research Decision: Quantitative and Qualitative Perspectives. (2nd Ed.),Toronto: Harcourt Canada.

[9] World Commission on Environment and Development (1987). Our Common Future. London, UK: Oxford University Press.

[10] Aikenhead, G. S. (2006). Cross-Cultural Science Teaching: Rekindling Traditions for Aboriginal Students. In Y. Kanu (Ed.), Curriculum as Cultural Practice (pp.223248). Toronto, ON: University of Toronto Press.

[11] Snively, G. \& Corsiglia, J. (2001). Discovering Indigenous Science: Implications for Science Education. Science Education. 85, 6-34.

[12] van Eijick, M., \& Roth, W. M. (2007). Keeping the local local: Recalibrating the status of science and traditional ecological knowledge (TEK) in science education. Science Education, 9, 926-947. 